\title{
ESFERA PÚBLICA AMBIENTAL - DAS NOVAS RELAÇÕES EMPRESA (MERCADO), ESTADO E SOCIEDADE
}

\author{
ENVIRONMENTAL PUBLIC SPHERE - THE NEW RELATIONS COMPANY \\ (MARKET), STATE AND SOCIETY
}

João Vicente R. B. Costa Lima ${ }^{1}$

\section{RESUMO}

O presente artigo mapeia, identifica e analisa as novas conformações relativas às interfaces entre o Estado (e o funcionamento das instituições democráticas), o Mercado (através das novas disposições da empresa capitalista na contemporaneidade) e a Sociedade. Trata-se uma realidade que - ao lado da conhecida realidade das limitações da sociedade democrática e suas instituições para se anteciparem aos problemas socioambientais, e da ênfase sobre as políticas e ações regulatórias de natureza coercitiva - as ações das empresas vigem para além das margens da regulação Estado/Mercado, sedimentando um campo que denota uma conexão direta entre a Sociedade e o Mercado. A presente análise tenta compreender essa nova dinâmica, suas conexões e consequências para a estruturação do macro e do micro mundo socioambiental. Destaca como emergente e relevante, na cena socioambiental, a figura do cidadão-consumidor.

Palavras-chave: Esfera pública ambiental. Cidadão consumidor. Racionalidade empresarial.

\footnotetext{
${ }^{1}$ Doutor em Sociologia e Professor do Instituto de Ciências Sociais da Universidade Federal de Alagoas, email para contato: jvcostalima@gmail.com.
} 


\section{ABSTRACT}

The present article maps, identifies and analyzes the new conformations related to the interfaces between the State (and the operation of democratic institutions), the Market (through the new arrangement of the capitalist enterprises in contemporaneity) and Society. It is about a reality in that - together with the known reality of the limitations of the democratic society and its institutions to anticipate themselves to the socio-environmental problems, and the emphasis on the coercive regulatory actions and policies - the actions of the enterprises be in use beyond the line of the Market/State regulations, consolidating a field which denotes a direct connection between Society and the Market. The present review tries to understand this new dynamics, from its connections and consequences to the organization of the macro and micro socio-environmental world. It highlights as emerging and relevant, in the socio-environmental scenery, the image of the consumer citizen.

Key words: Environmental public sphere. Consumer citizen. Business rationale.

\section{INTRODUÇÃO}

Tomando-se em consideração um imbricado de fenômenos e processos socioeconômicos, políticos e jurídicos que confluem para o terreno movediço em que se situa o campo ambiental, é mister mapear, identificar e analisar as novas conformações relativas às interfaces entre o Estado (o funcionamento das instituições democráticas), o Mercado (as novas configurações da empresa capitalista na contemporaneidade) e a Sociedade.

De um lado, muito se escreveu sobre um dado complexo da realidade: a sociedade democrática (suas instituições e procedimentos) está sempre a um passo atrás na busca por equacionar problemas ambientais de domínio público (LIMA, 2008). O traço destacável é o da incapacidade de antecipação dos problemas. A esfera pública é entendida como lugar rico de produção de sentido para o agir segundo uma vontade de mundo ou comunidade de destino, um lugar em que os indivíduos discutem sobre o presente e o futuro da vida coletiva, de forma egoísta e/ou cooperativa, não somente dentro do disciplinamento partidário e eleitoral, mas em um espaço público significativo mais amplo e indeterminado, perpassado por estímulos de conflitos e tensões entre um tal jogo de forças e de embates discursivos sobre os diversos projetos de mundo (ARENDT, 1997).

Nesse cenário, as instituições públicas movidas por interesses ambientais ganham importância em um contexto de enfrentamento entre conservacionistas e desenvolvimentistas, em suas respectivas formas mais nuançadas, seja atuando no plano regulatório, seja no plano coercitivo, enfim, um conjunto de ações institucionais que parecem conotar uma ampliação do público para tomar o sistema econômico sob certo regramento e controle. Instituições e organismos da Justiça, órgãos executivos como o IBAMA e entidades independentes como as ONG's representam e operam esse conjunto de novos atores na cena socioambiental, cuja atuação tem grande repercussão.

As empresas econômicas, por sua vez, são colocadas sob suspeição e tomadas como o grande alvo das iniciativas institucionais regulatórias. Classicamente entendidas como depredadoras e poderosas o suficiente para fugir do controle público, o enquadramento das empresas dentro de uma nova ordem política e jurídica passa a ser sintomático de um novo estágio de desenvolvimento das instituições político-democráticas no mundo e no Brasil.

Todavia, a cena socioambiental registra um acúmulo de ocorrências de novas disposições e ações das empresas relativamente às preocupações clássicas quanto à conservação da natureza e à justiça social. Estranhadas de pronto, quando ainda no início, essas ações, fruto de políticas corporativas desafiadas por novos condicionantes da concorrência econômica, ganharam em escala e em importância. Essas ações empresariais não têm correspondência com as 
ações coercitivas do poder público, simplesmente. Trata-se de uma realidade que passa, em boa medida, ao largo da regulação Estado/Mercado, para sedimentar uma linha direta entre a Sociedade e o Mercado.

Assim, o entendimento dessas ações empresariais no campo socioambiental de natureza da precaução e da justiça social precisa deparar-se com um questionamento ainda mais amplo e, ao mesmo tempo, pontual: (I) se a análise das empresas movidas por conteúdos sustentáveis, de forma geral, recoloca a relação entre ambiente e sociedade em outras/novas bases, porque informariam os novos contornos para as instâncias do Estado, da Sociedade e do Mercado e; (I) se, especificamente, na conexão entre a dimensão sociopolítica - onde está situado o novo cidadão-consumidor - e a econômica - onde os atores do mercado (empresas) se veem obrigados a incorporar valores e práticas mais sustentáveis em meio às dinâmicas competitivas - não se obtém um novo arranjo mais equilibrado com respeito aos interesses do lucro das empresas e os interesses da sociedade com vistas à consecução de padrões mais socioambientalmente sustentáveis. Tal hipótese, no entanto, enfrenta obstáculos hercúleos. De um lado, sacramentouse a incompatibilidade entre valores e práticas econômicas das empresas e os projetos de preservação da vida (humana e natureza), pela vigência de uma força arrasadoramente egoísta da empresa capitalista incapaz de mover-se por valores coletivos de responsabilidade e comprometimento com a conservação da natureza e a justiça social ${ }^{2}$.

Dado que ocorre a adesão cada vez maior de grupos de empresas de diversos segmentos que, espontânea ou coercitivamente (por pressões de natureza legal ou advindas do próprio mercado), aderem aos programas e às ações de responsabilidade "socioambiental", torna-se relevante, para a sociologia, analisar as implicações, nos contextos sociais e econômicos difusos, dos discursos e das práticas das empresas relativas à temática. Uma dimensão analítica em que se desenvolvem as ações das empresas precisa ser considerada em suas nuances: as empresas, para os fins últimos de obtenção de lucro, parecem adentrar, de forma mais visível e com certo desconforto, em uma arena política, porque se deparam com demandas advindas de diversos segmentos da sociedade civil organizada e voltadas aos motivos socioambientais. Ressalve-se, neste ponto, que a empresa capitalista sempre teve que se relacionar com as distintas esferas da vida (política, jurídica, cultural), mas mudanças de perspectivas parecem estruturar novos padrões de atitudes. Essa esfera política apresenta interfaces complexas, pois envolve indivíduos e grupos situados em níveis local e global, que racionalizam com base em matrizes diversas de visões de mundo e que, ao final, necessariamente não conformam um mundo socioeconômico e político perfeitamente balanceado e equilibrado. Portanto, as respostas das empresas guardam coerência e conectam duas ordens de realidade: (I) a nova ação econômica conserva profunda sintonia com as novas exigências (valores) advindas da (II) esfera pública. A ação da empresa capitalista, no plano político, está devidamente articulada aos desafios competitivos que se enfrentam na conquista de e na manutenção de novos mercados. Vantagens comparativas e relativas que advenham das ações socioambientais são mais facilmente concebidas e operacionalizadas. Contudo, seria simplificador concluir que as empresas agem, no campo socioambiental, somente com viés estratégico ${ }^{3}$.

\footnotetext{
2 Sobre este se recomenda a leitura do artigo "As possibilidades de uma socioecologia em Amartya Sen" (LIMA, 2008).

3 Este é o caso da moratória da carne levada a cabo pelas grandes redes de supermercados do país. 0 consumidor mediano brasileiro, ávido por incluir-se em padrões mínimos de consumo, não observa prioritariamente a origem da carne que come, senão o preço. Por que as grandes empresas atacadistas realizariam um boicote tão severo? Os resultados já são conhecidos. Fazendeiros e frigoríficos amazônicos correm contra o tempo para ajustarem-se a padrões mais sustentáveis, em meio à queda rigorosa na comercialização da carne que produzem. Vide http://www.noticiasdaamazonia.com.br/9178-supermercados-vao-boicotar-carne-da-amazonia/.
} 
Ressalte-se que as abordagens acadêmicas sobre as ações da empresa capitalista com vistas à realização de lucros sempre identificaram um ambiente econômico autônomo - no sentido de um ambiente constituído por uma lógica própria e regulado por princípios e mecanismos intrínsecos de funcionamento - a ponto de se poder visualizá-lo como entidade desconectada dos ambientes político e social, para citar apenas duas dimensões de realidade.

Dessa forma, ganhou visibilidade uma teoria do agir econômico a partir da qual a função primordial da empresa capitalista estava expressa na teoria da maximização de utilidades, que supunha que preocupações de ordem socioambiental não deveriam ser objeto do interesse e dos esforços da empresa econômica porque constituiriam um papel precípuo do Estado e de outros organismos correlatos. As empresas deveriam focar-se somente na busca de maior rentabilidade e lucro para os seus acionistas (FRIEDMANN, 1970). De outra forma e contemporaneamente, adquiriu grande relevo a abordagem de que preocupações das empresas com variáveis sociais e ambientais conectadas ao bem-estar das comunidades circundantes e do cidadão-consumidor não podem ser estranhas à racionalidade empresarial. Se em um tempo preocupações desse quilate podem significar custos adicionais que diminuem as margens de lucro e ameaçam a sobrevivência da empresa, em outros contextos de competitividade ou as empresas consideram essas variáveis na equação do seu negócio ou, decisivamente, podem ter a sua sobrevivência no mercado ameaçada. O tempo perfeito em que um contexto de competitividade econômica corresponde a padrões específicos depende de uma estrutura à parte das empresas para fazerem os diagnósticos e prospecções correspondentes aos seus respectivos segmentos empresariais e das necessidades de ajustamento às demandas não-econômicas (políticas) que chegam ao ambiente econômico.

Os desafios colocados às empresas no sentido de buscar padrões sustentáveis para o bom andamento de seus negócios exigiram a atenção e o desenvolvimento da habilidade de diálogo com as comunidades ${ }^{4}$, por parte da empresa capitalista, a ponto de considerar efetivamente os valores desses indivíduos, com impacto em seus processos de gestão e produção. Toda a informação advinda do difuso ambiente sociopolítico passa a afetar, de forma complexa, o ponto de vista das empresas. Do contexto político mais difuso, segmentos de empresas classificam certas demandas de indivíduos e grupos como, rigorosamente, disfuncionais do ponto de vista dos fins próprios à agência econômica, mas fruto das expectativas não cumpridas pelo Estado. Os limites para a ação, no campo socioambiental, por parte das empresas, é um tema à parte e de difícil equacionamento. De toda forma, essas demandas das comunidades, muitas vezes, chegam com tal ênfase que as empresas precisam responder com iniciativas que denotem comprometimento - seja no campo educacional, sejam ações outras para a minimização dos efeitos da pobreza e da desigualdade, para citar duas situações típicas. Daí que se fixa, via de regra, somente a visão rígida da empresa como agente egoísta em um mundo egoísta (mercado), restando a visão final das ações socioambientais como peças de propaganda, muito mais do que ações efetivas que denotes comprometimento real com o público.

A realidade, contudo, ganhou contornos menos marcados e, acreditam-se, as relações e instituições econômicas são constituídas socialmente a partir de novos elementos de valor que - para além do sentido vislumbrado por Durkheim, que se referia aos elementos não contratuais voltados aos substratos morais mais amplos que sedimentam o social - apontam para uma

\footnotetext{
${ }^{4}$ As empresas são compelidas a criar uma estrutura paralela à sua atividade fim para realizarem um conjunto de atividades voltadas a formas diversas de relacionamento com grupos humanos diversos, com abordagens apropriadas para os projetos de interesses da comunidade e outros atores situados na arena socioambiental, como os stakenholders.
} 
configuração peculiar, pelos valores evocados, no tempo-espaço das esferas de produção e consumo contemporâneas, atormentadas pelos imperativos de uma ação econômica sustentável.

A sociologia econômica e a sociologia ambiental ponderam essa discussão sugere desafios voltados ao imbrólio economia versus ecologia e ao duplo sociedade/mercado. As novas atitudes das empresas representariam convergência ou divergência no que se refere à causa da conservação da natureza? Estas novas disposições das empresas, para se ajustarem a padrões mais sustentáveis de atenção à natureza bem como à causa da justiça social, seja por motivações egoístas e/ou cooperativistas, ilustrariam a vigência de uma nova ordem moral que reverbera no conjunto das ordens política, social, jurídica e econômica ou somente trata-se de uma resposta estratégica da empresa capitalista ao problema ecológico reivindicado pelo sujeito-consumidor?

\section{LIMITES DA REGULAÇÃO DO ESTADO SOBRE O MERCADO (EMPRESAS)}

A racionalidade da empresa capitalista clássica sempre esteve premida pelo aumento da produção e a diminuição de custos, pesando os meios relativamente ao incremento de suas margens de lucro. Em um tempo hipotético que se poderia nomear de marco zero, ou se otimizava o uso de mão-de-obra e dos insumos (destaque-se, recursos naturais) ou a sobrevivência no mercado estava sob risco. Assim sendo, estavam dados os elementos para a consecução da maximização da utilidade. Esse tempo (marco zero) - que bem pode, hipoteticamente, ser situado em um intervalo linear razoável (o início da modernidade capitalista) e, ao mesmo tempo, evoca padrões reconhecidos no tempo presente -, propunha consequências trágicas para a conservação da natureza e o bem-estar social porque não submetidos a instrumentos legais regulatórios.

O papel regulador do Estado, a partir do século XIX, criou os primeiros mecanismos atenuadores (ainda que muito incipientes) dos efeitos extremos das ações econômicas predatórias sobre o meio ambiente e as populações, nas bases fenomênicas da desigualdade social e da pobreza. Para as empresas, no marco zero, era dispendioso e arriscado assumir posturas próativas no que tange aos impactos de suas atividades sobre o meio ambiente e sobre as populações. Posturas pró-ativas significavam, àquele tempo, redução de competitividade e perdas de vantagens comparativas relativamente à consecução da maximização do lucro. No caso brasileiro, somente em meados da década de 1980, verifica-se algum impacto da legislação ambiental, de fato, afetando a racionalidade das empresas. Um cenário simplificador parecia mostrar as bases em que se firmavam as primeiras iniciativas das empresas: em atenção à legislação vigente, as empresas ajustavam as suas condutas de natureza mitigatória, porque não auferiam maiores ganhos de imagem, ao mesmo tempo em que impunham um aumento de custos. Por este tempo, observa-se um aumento e a eficácia da legislação e dos organismos estatais de controle, da pressão política das Organizações Não Governamentais (ONG's), além, e ainda que em pequena escala, de um processo rico de ramificação dos temas, valores e da agenda ambiental nos universos social, político, jurídico e cultural brasileiros.

É razoável supor que, em um dado nível, os governos têm um poder de indução efetivo. Contudo, é preciso que se reflita sobre as políticas públicas e programáticas que o Estado brasileiro engendrou ao longo dos últimos vinte anos e também das consequências que produziu nos estímulos ou não à (re)estruturação das bases da economia brasileira com respeito aos motivos socioambientais. De outro forma, em outro nível de atuação do Estado, também é importante que, minimamente, se reflita sobre a extensão e a profundidade dos mecanismos do poder público para produzir todos os regramentos e, de forma predominante, conduzir os atos execu- 
tivos - seja na implementação de políticas, seja na fiscalização dos atores (públicos e privados) na condução de seus projetos econômicos, em menor ou maior escala e alcance.

\section{GOVERNOS E POLÍTICAS PÚBLICAS}

Eduardo Viola (1998) analisa as políticas públicas do governo do presidente Fernando Henrique Cardoso (1994-2001) para a área ambiental, identificando-as como limitadas e fragmentadas, além de fragilizadas do ponto de vista gerencial. As políticas ficaram isoladas dos centros de decisão econômica porque eram secundárias no que tange às prioridades das formulações governamentais relativamente ao desenvolvimento. O núcleo decisório do governo, que formulava as diretrizes fundamentais da economia, não ponderou o impacto da revolução ambiental nos processos produtivos (eficiência energética, reciclagem de materiais, controle total de poluição e ecodesign) sobre o modelo de desenvolvimento econômico e os seus desdobramentos em processos econômicos concretos. Por isso, avaliava a sustentabilidade ambiental como um obstáculo ao desenvolvimento econômico, o que explica o veto silencioso para a implantação da $\mathrm{CIDES}^{5}$.

O principal componente da política industrial mais importante àquele tempo - a política automobilística - pouco inovava, porque estava centrada apenas no mote de atração de novos investimentos estrangeiros para maximizar a produção de carros sem considerar efetivamente as questões relacionadas à promoção do transporte coletivo, ao aumento da eficiência energética e à diminuição de poluentes dos veículos ${ }^{6}$.

As demais políticas - reforma tributária, política energética e agrícola - sofreram com os sinais ambíguos do governo no que se refere a tornar as preocupações ambientais para o centro de seu planejamento, de decisões e ações. A reforma tributária não avançou no sentido de induzir uma produção e um consumo mais parcimonioso, desviou-se da discussão e da introdução de um imposto ambiental que incidisse sobre a poluição, o uso de recursos naturais, o consumo ineficiente de energia e o desperdício de materiais. A política energética foi marcada pela falta de direcionamento de longo prazo e que valorizasse a conservação da energia e o uso de energias renováveis ${ }^{7}$, de modo que o petróleo manteve-se como a grande prioridade. A política agrícola não enfrentou os três problemas fundamentais do ponto de vista da produção: 0 desperdício de produtos na colheita, estocagem e transporte; a falta de incentivos econômicos para a conservação dos solos e mananciais; além do uso excessivo de agroquímicos. Do ponto de vista social, uma reforma agrária limitada e divorciada dos preceitos da sustentabilidade esteve em agenda tanto por parte do governo quanto das lideranças do MST.

Ferreira (2000) interpreta a atuação do Estado, no trato das políticas públicas ambientais, como um paradoxo: ao mesmo tempo em que demandas sociais emergem em decorrência da crise ambiental e da disseminação de situações de incerteza que requerem a intervenção da instância política e administrativa do Estado, é notória a perda de capacidade do Estado em determinar os rumos principais da dinâmica social e em proporcionar políticas eficientes.

\footnotetext{
5 A Comissão Interministerial para o Desenvolvimento Sustentável (CIDES) foi criada por Itamar Franco (junho de 1994), em cumprimento a uma determinação da Comissão de Desenvolvimento Sustentável da ONU. A CIDES foi objeto de disputas intra e interministeriais (MMA, Planejamento, Ciência e Tecnologia e Relações Exteriores) a respeito de qual instância coordenaria as políticas de sustentabilidade ambiental do governo.

6 O sucesso da política automobilística aumentou o congestionamento de trânsito nas cidades e elevou as emissões de $\mathrm{CO} 2$ e poluição, com a consequente diminuição da qualidade de vida.

7 As boas iniciativas, nesse campo, têm menos a ver com iniciativas governamentais: a instalação de médias e pequenas hidroelétricas, energia solar, eólica, biomassa.
} 
Questiona-se o modelo de gestão do Estado com respeito à sua capacidade ou não para gerir políticas públicas eficientes e sustentáveis. Considerando-se as ações pró-ativas dos movimentos sociais, empresários, sociedades científicas, sindicatos, etc., ganha contorno uma indagação ímpar: é imperativo atribuir somente ao Estado um papel preponderante na formulação, na implementação e no gerenciamento de políticas sustentáveis? As análises da configuração de poder que viabilizam ou não a instrumentalização de políticas ambientais mostram que a inanição do Estado não pode ser compreendida somente como gestão ineficiente, como se a ineficiência fosse um atributo natural e constitutivo do Estado. De todo modo, novas demandas socioambientais desafiam os códigos e os instrumentos de gestão da vida pública, fazendo o tema da necessidade de reinvenção do Estado ganhar mais importância ${ }^{8}$.

Contudo, sabe-se que tanto modelos de desenvolvimento como tipos de Estados guardam correspondência com os tipos de regimes políticos e graus de participação democrática. 0 modelo de Estado mais avançado na gestão socioambiental ocorre em ambientes de cultura política mais amadurecida. As melhores abordagens para os problemas socioambientais mostraram-se sistêmicas, e não tradicionais e fragmentárias - predominantes da gestão pública e derivadas de demandas setorizadas e pulverizadas ao longo de diversos ministérios, secretarias e departamentos em vários níveis, como se a realidade fosse perfeitamente compartimentalizada.

Muitas expectativas foram colocadas quanto à atuação dos organismos do Estado para disciplinar as ações, principalmente, econômicas, de todo tipo. Este momento em que foram criadas instituições públicas, leis, códigos e resoluções, representou, sem dúvida, um desenvolvimento da vida democrática no país. Entretanto, como se verá a seguir, não resolveu todos os problemas que todos os seus instrumentos de controle pareciam propiciar.

\section{MARCO REGULATÓRIO E INSTRUMENTOS DE COERÇÃO}

Um cenário regulatório que se firmou na vida institucional brasileira dá conta da relação entre a empresa capitalista (Mercado) e o Estado (com seus organismos e seus instrumentos operativos $)^{9}$. Destaque-se a promulgação da Lei Federal 6.938, de 31 de agosto de 1981, que instituiu a Política Nacional do Meio Ambiente e criou, para a sua execução, o Sistema Nacional do Meio Ambiente (SISNAMA). O SISNAMA tem como órgão superior o CONAMA e como órgão central o IBAMA, sendo ainda constituído pelos órgãos e pelas entidades federais, estaduais e municipais. Sua atuação destina-se à produção de regramentos, nesses níveis de governo, voltados ao uso racional dos recursos ambientais, à preservação da qualidade ambiental e à mitigação dos prejuízos ambientais. Por este ato político, verificou-se (pelo menos como pretensão) uma mudança no enfoque das prioridades da ação governamental, antes comprimida no campo do desenvolvimento econômico.

Contudo, a Lei 6.938 considera o meio ambiente como patrimônio público a ser assegurado e protegido, privilegiando o aspecto preventivo do controle ambiental. Daí derivaram diversos instrumentos da Política Nacional do Meio Ambiente: (I) o estabelecimento de padrões de qualidade ambiental; (II) o zoneamento ambiental; (III) a avaliação de impactos ambientais; (IV) o licenciamento e a revisão de atividades efetivas ou potencialmente poluidoras.

\footnotetext{
8 Mas, voltando à discussão sobre o que é o Estado: (1) é preciso afastar noções do Estado como um corpo monolítico, porque homogêneo; (2) no interior do Estado, e entranhados no governo, diga-se no nível das políticas públicas ambientais, operam estrategicamente atores coletivos diversos e conflitantes até, focados na consecução de seus projetos, baseados em suas crenças e motivações sobre as melhores políticas para o meio ambiente. Há uma diversidade de policymakers dentro de um mesmo governo.

9 Vide Verdun (2006).
} 
Juntamente com os instrumentos que a nova política propunha, instaurou-se uma mecânica da regulação: empresas que querem realizar os seus empreendimentos precisam adequarse à legislação e ao controle das entidades do Estado, como o IBAMA e o Ministério Público. Funciona, aqui, um mundo de regras e procedimentos que garantiriam padrões mínimos de sustentabilidade. Entre os indivíduos e as empresas conta-se, desde então, com a presença do Estado municiado para produzir leis e garantir-lhes o respeito. Este seria um campo da realidade estruturada e regulada que comporta aspectos da realidade socioambiental notadamente de natureza da precaução e coerção. Aqui, os órgãos do Estado atuariam de maneira a garantir que a sociedade não seja penalizada pela ação imprudente e gananciosa dos agentes econômicos. Entretanto, após um tempo mínimo de operação das novas leis, resoluções e instituições competentes disciplinando as condutas humanas relativamente ao uso dos recursos naturais, algumas indagações sedimentaram-se e apontavam para os aspectos redutores que toda essa institucionalidade não foi capaz de abarcar: os instrumentos do Estado disciplinando esse campo da realidade - das ações predatórias econômicas de agentes públicos e privados - são completamente capazes de ordenar esse nível da realidade socioambiental? A questão socioambiental da produção e da gestão econômica em bases sustentáveis está plenamente atendida na perspectiva que esse tal ordenamento legal produz? A resposta parece indicar para campos e níveis da realidade foras do alcance do funcionamento desta nova institucionalidade que a Lei 6.938 produziu.

Não se pretende, neste ponto, afirmar proposições na direção de uma negação do papel do Estado. De pronto, mesmo reconhecendo os seus limites, é indiscutível a importância do Estado regulando aspectos da vida coletiva, como os projetos econômicos imprudentes. Mais que isso, algumas ações regulatórias são, de fato, mais eficazes se mantidas sob a tutela do Estado, e não de outras instâncias privadas e seus interesses.

Mas, é importante vislumbrar outros cenários ilustrativos do campo socioambiental. Em um desses cenários, pode-se ressaltar a regulação das ações dos agentes econômicos (empresas públicas e privadas) por instâncias oriundas do mundo não-econômico, mais especificamente da sociedade, e ainda de forma mais pontual de Organizações Não Governamentais (ONG's), que operam como entidades certificadoras instaurando outra ordem institucional e de procedimentos para este fim. Alguns exemplos ganham espaço na opinião pública qualificada e leiga: o Selo Verde ligado às atividades de florestamento e reflorestamento, e o selo Free, voltado às atividades da construção civil.

Dessa forma, entre as ações das empresas e os indivíduos tem-se outro agente não governamental que mede a relação socioambiental. Estas ONG's certificadoras garantem ao cidadão-consumidor que o produto, comprado e consumido, guarda garantias relativas à sustentabilidade dos processos e de outros resultados. O fator indutor da cena é o cidadãoconsumidor: através do consumo, o indivíduo expressa uma ordem de valores que afeta a realidade econômica em algum nível. As empresas e os seus empreendimentos (conectados sinceramente ou não aos preceitos de uma sociedade sustentável) adequam-se e ajustam-se às novas orientações de consumo do cidadão. Esse campo da realidade socioambiental é difuso e heterogêneo: não acontece em todos os setores econômicos com a mesma velocidade e intensidade; são iniciativas microscópicas em meio à realidade complexa. Este é o caso da construção civil no Brasil, haja vista que um percentual cada vez maior de construções são feitas dentro de parâmetros de certificações ambientais ${ }^{10}$, sendo que o processo todo é iniciado pelo perfil do consumidor em obter produtos dentro de certos parâmetros.

10 Vide http://www.vanzolini.org.br/conteudo.asp . 
Essa dinâmica de mediação (empresas/cidadão-consumidor) por entidades da sociedade civil é resultado de esforços da sociedade, não somente para não se submeter aos controles do Estado ${ }^{11}$, mas pelo reconhecimento dos limites do poder estatal para dar conta de todos os níveis de interação sociedade/mercado. Esse campo da realidade sustenta-se pela confiança: o cidadão-consumidor tem fé nas entidades certificadoras, acreditando que estas, através de uma processualidade e parâmetros críveis, autênticos e efetivos, informam às empresas, produtos e seus respectivos processos dignos de certo status socioambiental parcimonioso. Acrescente-se, neste aspecto, que há todo um processo de legitimação dessas entidades certificadoras. As entidades buscam (por seus valores de regulação evocados e por suas práticas) dar credibilidade às suas ações através de duas ordens. De um lado, há as iniciativas de natureza política, como é a criação de um (1) Conselho Consultivo que congrega membros de associações científicas; e de um (2) Conselho Deliberativo, que congrega entidades politicamente ativas na cena socioambiental (WWF; Green Peace, etc.). Nesses dois níveis, são gestados os padrões e os parâmetros públicos. A transparência das ações e os procedimentos para fins de certificação geram, ao final, os efeitos esperados de fé pelo cidadão-consumidor. O círculo fecha-se porque toda essa institucionalidade baseia-se em um conjunto de conhecimentos científicos e técnicas que garantem as medições e as avaliações quali-quantitativas relativas às realidades biofísicas e antrópicas que subjazem às iniciativas econômicas sob análise.

Um exemplo a ser analisado é a entidade certificadora Forest Stewardship Council (FSC) e o Selo Verde, o qual foi criado para as atividades de florestamento e reflorestamento. Notadamente podem reivindicar o Selo Verde tanto as grandes empresas de reflorestamento (ARACRUZ; Stora Enso; Votorantim), quanto pequenos empreendimentos (cooperativa extrativista no Acre). Os padrões e os parâmetros de certificação alcançam o plano biofísico (manejo, processos, preservação da fauna e flora, graus de controle e uso de químicos para adubação) e humano (qualidade de vida das comunidades) ${ }^{12}$. As empresas que aspiram à certificação precisam arcar com custos para realizar as avaliações e os monitoramentos que são exigidos. Os próprios parâmetros e os indicadores obrigam que a empresa ajuste-se a um espectro amplo de condutas que mostram um enquadramento aos códigos, às leis, às resoluções e aos demais instrumentos legais e técnicos circunscritos à cultura política, jurídica e técnica do país. A FSC não é uma empresa que se propõe ao lucro e sequer pode ser vista como um negócio. Tal dado gera vários desdobramentos: porque a FSC não vive desse recurso, autoriza que outras empresas conduzam o processo de certificação (CERFLOR e IMAFLORA, no caso brasileiro). A empresa interessada em obter a certificação precisa realizar gastos que aumentem os seus custos, pela obrigatoriedade em adotar os novos parâmetros, os processos e os procedimentos bem como pelas comprovações científicas que são exigidas e que são feitas por consultorias críveis (especialistas das universidades e centros de pesquisa, dentre outros). Esta disposição é uma medida primeira do nível de comprometimento da empresa no uso parcimonioso dos recursos naturais e de preocupação efetiva com as comunidades afetadas. Por estes custos adicionais, a madeira certificada é mais cara que a madeira não-certificada; assim, a estrutura só funciona porque tem um consumidor motivado e capitalizado para pagar mais pelos produtos de madeira certificada.

\footnotetext{
${ }^{11}$ Esta é, em si, uma temática formidável que perpassa debates políticos e intelectuais calorosos sobre a natureza da democracia e de suas instituições, como é o caso de se estabelecer os limites para a ação de governos no que tange ao espaço do privado, aos direitos individuais, entre outros assuntos palpitantes.

${ }^{12}$ Estes parâmetros e indicadores são, como é próprio do fazer científico, sujeitos à controvérsia, que é minimizada pelas exigências públicas de transparência e de debates e consultas públicas.
} 
À luz do que foi informado até aqui, duas ordens de questões (com suas correspondentes origens e influências teóricas) emergem como incongruentes se colocadas lado a lado:

(I) A solução para a insustentabilidade econômica (de uma lógica econômica predatória operante) de hoje pode ocorrer via mercado/consumo. O mercado econômico pode ser fator importante de soluções que atenuem e reequilibrem o intercâmbio humano à natureza; e

(II) Se a ação econômica strictu senso é auto-interessada e egoísta (e enriquecer pode significar destruir o outro tipo humano e a natureza ao redor), como pode emergir outra substância não-egoísta no seio do capitalismo de maneira a recuperar componentes de sentimentos públicos compartilhados?

O enfrentamento do (aparente) (?) paradoxo entre os pressupostos do enunciado (I) em relação ao enunciado (II) só podem ser, inicialmente, tratados a partir do redimensionamento da função econômica, tomada como constitutiva da vida humana, individual e coletiva. Lançandose mão da categoria econômica clássica do trabalho, para exemplificar (que supõe o intercâmbio que os homens estabelecem com outros homens e a natureza para prover as suas necessidades materiais), verifica-se a sua extensão, profundidade e riqueza no sentido de que os conteúdos motivacionais egoístas não se reduzem a uma ação que, ao final, gere ganho para um indivíduo em detrimento do conjunto, nem que a ação conecte-se a uma substância estritamente a-éti$\mathrm{Ca}^{13}$. É preciso afastar uma crítica da ação econômica egoísta que apregoa a extinção da função econômica porque todos os problemas irremediáveis seriam produzidos pela substância capitalista. Esta proposição, que mais se aproxima de uma peça retórica, ignora que a abolição da função econômica é uma impossibilidade lógica, econômica e sociopolítica. Obviamente que não se quer criticar posições ideológicas com base em irracionalismos. Nesse sentido, sempre será o tempo para indagar sobre o que é mesmo a função econômica. A sociologia econômica pode ajudar, e mesmo a economia: a função econômica é um meio para um fim. E, mais, mostramos nossos valores últimos nos atos de consumo. Eis o ponto que remete ao cerne da discussão até aqui realizada. Os indivíduos racionais e sugestionados por visões de mundo (novas, modificadas) adentram no mundo do mercado quando operam como consumidores, com base em valores não egoístas ${ }^{14}$.

Vale ainda explorar o postulado do mercado como a oficina do diabo. No campo econômico só germinaria uma experiência vital que alteraria nossos sentidos: nos tornaríamos egoístas e mesquinhos; sentimentos de cooperação, solidariedade e de comprometimento com os dilemas humanos vividos por outrem seriam abolidos. Pressupõe-se que fora dos domínios econômicos da vida, haveria uma chance para a emergência de uma substância humana altruísta. Diante da radicalidade da teoria da oficina do diabo, pergunta-se: somente fora do mundo econômico vigora o viver solidário e de comprometimento sem as impurezas do egoísmo? Será que se pode afirmar que, nas relações familiares, no interior das instituições religiosas e comunitárias, nos movimentos sociais e nas diversas formas de sociabilidade não-econômicas, não vigorariam elementos de poder e egoísmo? Se o mundo econômico é a única esfera em que se sedimentam interesses e ações egoístas, como entender as relações de opressão dos homens sobre as mulheres, as relações de intolerância étnica e de outra natureza? É razoável que a esfera econômica gere seus valores com uma volúpia tal que possa penetrar outras esferas da

\footnotetext{
${ }^{13}$ Amartya Sen (1999) e sua Sobre Ética e Economia contribuem com uma rica reflexão acerca da pertinência em se recuperar elementos éticos quando se reflete sobre a natureza da ação econômica e outros desdobramentos.

${ }^{14}$ Por que um indivíduo pagaria mais por um produto com mesmo valor de uso? Todavia, não se pode afirmar que todos os consumidores sobre todas as questões econômicas (e mercados) se comportarão desta maneira.
} 
vida, em uma lógica egoísta estrita. Mas, daí derivar que, para sempre e em todo lugar onde as interações humanas acontecem, este será o único ingrediente que conecta as pessoas, parece um excesso. Hipóteses sobre a ação egoísta devem ser sempre tratadas como hipóteses sobre a ação egoísta, que precisam ser testadas no plano empírico e não em bases extremas como um $a$ priori sobre os segredos da alma humana e as suas manifestações nas instituições carnais.

As dinâmicas contemporâneas que mostram uma conexão direta entre a sociedade e o mercado são improdutivas, na perspectiva da teoria redutora da ação econômica como essencialmente egoísta, para demonstrar o contrário do que é afirmado pela teoria estabelecida, como seus "axiomas", de uma volúpia egoísta negativa operante: a sociedade pode muito pouco contra os recursos (econômicos e simbólicos) que os detentores do capital têm à mão. Desde o comportamento como consumidor, passando por outras instâncias em que os indivíduos estão direta e/ou indiretamente expostos às influências de instituições formadoras de opinião, o indivíduo comum no cotidiano é tratado como uma presa fácil, como entidade dócil e domesticável.

Contrariamente às teorias que entendem a sociedade como elo fraco em relação ao mercado (visto como instância indestrutível e inalcançável), verifica-se um conjunto de ações como base em valores - heterogêneas, espalhadas em campos diversos da vida coletiva nos quais os indivíduos encontram-se, reencontram-se, dialogam e negociam, contestam e convergem, em uma profusão de situações e na interface com o mercado. Todos os indivíduos transitam do mundo cotidiano e societário para o mundo econômico (quando trabalham e consumem), e o mercado nem se apresenta como uma unidade coerente e hermética, mas com brechas visíveis porque acolhe as influências difusas que vêm da sociedade. Nesse contexto, o cidadão-consumidor eleva-se e, com maior ou menor consciência, mais ou menos pessimista, mais ou menos altruísta e certamente interessado, ele desvia-se do campo de realidade onde opera Estado e seus instrumentos e lança-se numa nova situação ainda não necessária e devidamente regulamentada da esfera da vida socioeconômica. De outra forma, este campo novo da realidade está fora da jurisdição do Estado. A dinâmica Empresa (Mercado) /Sociedade Civil apresenta novos enraizamentos ${ }^{15}$.

É fundamental entender os componentes pragmáticos e ideais envoltos na cena: o público consumidor idealiza um mundo e o seu lugar nele, segundo valores (ideais). As empresas adequam-se a essa demanda motivadas pelos interesses conectados à maximização das utilidades, com base em (I) um cálculo de diminuição de custos, sem maiores considerações com preocupações socioambientais, porque focados apenas no retorno aos acionistas (maior lucro), (II) e/ou também guiadas por valores (ideais) ${ }^{16}$. Não é necessário esperar que todos os capitalistas convertam-se à causa ambiental para que seja dado início a um novo processo civilizador. Assim posto, um banco holandês comprou os créditos de carbono que a usina do lixo (aterro sanitário) da prefeitura de São Paulo produz. No seu país de origem, esta medida reforçou a imagem do banco como instituição comprometida com a causa ambiental. Seria razoável pensar que esta

${ }^{15} \mathrm{O}$ nascente Mercado de Carbono, o Fair Trade são exemplos deste movimento. Este último retrata uma série de iniciativas em que os consumidores do mundo pagam mais por produtos da agricultura familiar, pequena empresa que configure, em algum grau, uma ação que seja um contraponto à exploração. Estas iniciativas estão longe de provar o estabelecimento de um novo capitalismo dominante. Contudo, provam um dado que de tão básico choca, porque esquecido em diversas disciplinas preocupadas em provar a autonomização das esferas de realidade de objetos de suas disciplinas científicas: o homem econômico é concomitantemente um homem social, e os fantasmas que atormentam a sua alma podem sugerir-lhe os caminhos do bem e do mal, em um e outro campo da realidade.

${ }^{16} \mathrm{O}$ padrão comportamental (II) não ocorre desconectado da equação da maximização dos lucros relativamente à diminuição dos custos (I) e, acrescente-se, da disposição relativamente à concorrência. 
medida, por sua vez, tenha aumentado a carteira de clientes do banco. Para os puros de intenção, uma ação econômica pragmática deste tipo não é relevante para a consolidação de uma sociedade sustentável. Para os realistas, que importa se a motivação era mesquinha e egoísta, se, ao final, o objetivo de minimizar/diminuir o lançamento na atmosfera dos gases danosos tenha sido alcançado?

\section{A RACIONALIDADE SOCIOAMBIENTAL DA EMPRESA CAPITALISTA: MEIA VOLTA, VOLTA E} MEIA

No tempo presente, isto é, ultrapassado o hipotético marco zero, as empresas, de forma heterogênea, passam a adotar medidas que, se não deixam de ter a natureza mitigatória, trazem a novidade de incorporar ao nível de sua governança uma atitude pró-ativa no que tange aos novos processos e produtos, otimizando o uso de energia e matéria-prima, a reciclagem de resíduos. Se, do ponto de vista dos custos, não acontecem modificações maiores (e, talvez, até a sua ampliação), do ponto de vista da imagem da empresa (comprometida com o meio ambiente), os ganhos vêm pela visibilidade positiva. Para além das pressões legais, as empresas começam a mostrar-se preocupadas com as questões que afetam o cidadão comum na forma de certo voluntarismo ambiental corporativo. A palavra de ordem é antecipação aos problemas. No que concerne à variável competitividade, o novo ambiente relativiza as vantagens naturais de obtenção de mão-de-obra mais barata. O diferencial "preocupação ambiental", traduzido em práticas corporativas, parece produzir efeitos em uma nova dinâmica de concorrência. A compreensão de todo o processo só se completa quando se verifica a pressão política externa ao funcionamento do mundo econômico, fundada em novos hábitos de consumo sugestionados por novos valores morais e de uma ética socioambiental capaz de afetar a racionalidade das empresas. Velhas questões adquirem novo enquadramento: as demandas sociais reprimidas na forma de menores salários são reembaladas como parte de iniciativas que denotam preocupação social das empresas. O diferencial competitivo, aqui, trata de incorporar aspectos estranhos à fórmula antiga de maximização das utilidades e, desse modo, ficar indiferente a estas preocupações (como as demandas sociais reprimidas) pode significar a perda de mercado, de competitividade.

De volta ao começo, se, num tempo primeiro, as empresas podiam retardar a adoção de medidas porque adotaram uma postura mais cautelosa de observação dos cenários, no tempo presente é preciso ressaltar que essas mesmas empresas foram afetadas por uma multidão de indivíduos não necessariamente conectados em uma única entidade geradora de estímulos a partir dos quais, em diversos segmentos de negócios, as ideologias verdes mais ou menos superestimadas se tornaram partes efetivas do imaginário e da racionalização dos negócios das empresas. Não é possível mais ignorar um senso comum socioambiental que interfere mesmo em setores refratários aos novos valores e aos novos tempos. O mercado, por isso, precisou organizar-se e produzir os seus próprios regramentos, voluntários é certo, de um lado. As empresas podem não aderir. Mas, indiretamente, é obrigatório, uma vez que, para certos setores, não há muita margem para conduzir o negócio fora desses parâmetros. Uma indicação dessa tendência pode ser vista no movimento interno das bolsas de valores do mundo.

As bolsas de valores passaram a hierarquizar as empresas através de um índice de sustentabilidade, tornando-se um parâmetro importante para regular as ações no mercado de capitais. Estas empresas passaram a ser avaliadas como pertencendo ao ramo das mais inovadoras e empreendedoras, sendo vistas como investimentos menos arriscados. De outra parte, o sistema financeiro internacional e nacional passou a dirigir suas carteiras de financiamento atra- 
vés do filtro das demandas de responsabilidade socioambiental. É o caso das instituições do $A B N$ AMRO Bank, Barclays, Citigroup.

O centro decisório das empresas começa a operar considerando - para além dos atores/ instituições convencionais da equação tradicional, como concorrentes, clientes, distribuidores e acionistas - a interface com os conteúdos de valor oriundos da sociedade civil. A diversidade e a complexidade das cadeias produtivas e as empresas de diversos setores absorvem, de forma heterogênea, as influências "não-econômicas" sobre os seus respectivos negócios: se dependem de recursos naturais em abundância, se atuam em segmentos mais regulados por normas, se situados em ramos de alta competição por mão-de-obra qualificada, se mais ou menos suscetíveis às pressões do público consumidor sugestionado por uma nova ética do consumo parcimonioso, etc. Desses condicionantes, pode-se estimar padrões diferentes de disposições relativas às práticas corporativas de natureza socioambiental.

Esta postura permite um redimensionamento do ambiente econômico-político, sociocultural e jurídico. Se, outrora, as empresas eram tratadas como inimigas de causas ambientais e sociais, que precisavam ser vigiadas, disciplinadas e punidas, no tempo presente todas essas funções continuam sendo de extrema importância, mas são acompanhadas, em um plano paralelo, de novas condições de interação entre o mercado (e a empresa) e o público consumidor, em uma velocidade de estímulos que tem impactos similares ou até mais radicais (dependendo dos segmentos econômicos) que os ajustamentos de conduta obrigatórios gerados pelo poder público, de natureza coercitiva. A coerção, agora, passa a ser a pressão (difusa e heterogênea) do cidadão-consumidor. As empresas não estão obrigadas e estão obrigadas independentemente de sentimentos prosaicos de solidariedade e comprometimento.

\section{ALGUMAS CONSIDERAÇÕES A GUISA DE CONCLUSÃO}

A aprovação da Lei 6.938, nos anos de 1980 , prometia um novo marco na forma como a sociedade brasileira pensava e relacionava-se com o meio ambiente. Os valores e os objetivos ligados à conservação dos recursos naturais ganhavam um status nunca antes reconhecido. Sob certo ângulo, os ganhos eram robustos, não somente em termos de uma ordem institucional complexa criada para este fim, mas pelos resultados que começaram a ser produzidos no sentido de minimizar os males da ação humana predatória. Registre-se: sem maiores regramentos quanto ao uso dos recursos naturais, vigorava tão somente as ações segundo os interesses imprudentes das empresas (públicas e privadas). Saindo-se do extremo em que as atenções se voltavam para os valores e as práticas das ações econômicas predatórias sobre o meio ambiente (e a vigência de um predomínio negativo do antrópico sobre o meio ambiente), a lei colocava em relevo a realidade biofísica como entidade desconectada da dimensão humana. Em verdade, toda a condição é simplificada na figura do tipo humano genérico imprudente. A palavra-chave do novo mote ideológico é conservação da natureza das ações humanas genericamente tomadas como contendo uma essência inequívoca, egoísta e destrutiva. Nos últimos anos, ocorreu um debate profícuo no âmbito público que produziu - no sentido de recuperar - um rebalançeamento das variáveis da fórmula, fazendo que a dimensão humana perdesse um pouco do status de pura negatividade.

No contraponto do diagnóstico de Beck - sobre um cenário fatalista no que se refere aos padrões de conduta das empresas, principalmente industriais e do primeiro mundo, que conjugava perda de controle do público (meios institucionais frágeis) para controlar questões dessa natureza - a reflexão sobre as políticas e as práticas de responsabilidade socioambiental de 
empresas apresenta novos e intrigantes elementos para se pensar a relação entre função econômica versus função ecológica.

As políticas e as ações das empresas ainda não proporcionam fazer maiores exercícios de generalização, senão o mapeamento de mudanças que se configuram mais em tendências a serem observadas/confirmadas. O cenário continua ainda a ser o da empresa arrastada pelas máximas de diminuição de custos e de aumento da lucratividade do negócio, com a incorporação de fatores e políticas efetivas em um campo novo, conectados a motivos não-econômicos, no sentido de não ser a sua atividade específica. A novidade é o tipo humano do cidadão-consumidor eticamente motivado que, em grande escala, espalhado em campos diversos da economia, vem afetando de forma heterogênea a realidade do mercado.

As empresas reformulam os seus projetos de maximização de utilidades, incorporando o peso e o impacto da variável "cidadão-consumidor". As consequências disso, no sistema econômico-ecológico, ainda estão no plano estritamente do imponderável. Mas, é incontornável que se pense, como parte de uma mesma equação do agir econômico, os elementos de valor que denotam um agir com responsabilidade e comprometimento relativos à sociedade e ao meio ambiente, com impactos nos planos local e global. Lado a lado, os ingredientes de uma cultura capitalista egoísta e negativa precisam ser pensados à luz dos estímulos do agir ético e do comprometimento.

\section{REFERÊNCIAS BIBLIOGRÁFICAS}

ARENDT, Hannah. A condição humana. Rio de Janeiro: Forense Universitária, 1997.

ARACRUZ CELULOSE. Relatório anual de sustentabilidade 2006, 2007, 2008. São Paulo. Disponível em <http:/ /www.aracruzcelulose.com.br>. Acesso em 8 set. 2009.

BECK, Ülrich. Risk society: towards a new modernity. Londres: Sage, 1991.

CARNEIRO, Marcelo S. Crítica social e responsabilização empresarial: Análise das estratégias para a legitimação da produção siderúrgica na Amazônia oriental. Caderno CRH, Salvador, v. 21, n. 53, p. 323-336, maio/ago. 2008.

A construção social do mercado de madeiras certificadas na Amazônia: a atuação das ONGs ambientalistas e das empresas pioneiras. Sociedade e Estado, Brasília, v. 22, n. 3, p. 681-713. set./dez. 2007.

CHEIBUB, Zairo e LOCKE, Richard. Valores ou interesses? Reflexões sobre a responsabilidade social das empresas. In: KIRSCHNER, Ana Maria; GOMES, Eduardo R.; CAPPELLIN, Paola (orgs.). Empresa, empresários e globalização. Rio de Janeiro: Relume Dumará/FAPERJ, 2002.

DEMAJOROVIC, Jacques. Sociedade de risco e responsabilidade socioambiental: perspectivas para a educação corporativa. São Paulo: Senac, 2003.

DONAIRE, Dennis. Considerações sobre a variável ambiental na empresa. Revista de administração de empresas, São Paulo, v. 34, n. 2, p. 68-77, mar/abr. 1994.

DRUK, Graça; FRANCO, Tânia. Padrões de industrialização, riscos e meio ambiente. Ciência \& Saúde Coletiva, Salvador, v.3, n.2, p. 61-72, 1998.

ELSTER, Jon. Peças e engrenagens das ciências sociais. Rio de Janeiro: Relume Dumará, 1994. 
ESTY, Daniel C.; WINSTON, Andrew S. O verde que vale ouro: como as empresas inteligentes usam a estratégia ambiental para inovar, criar valor e criar uma vantagem competitiva. Rio de Janeiro: Elsevier, 2008.

FERREIRA, Leila da Costa. Ambiente \& Sociedade - Ano III - N. 6/7 - 1ㅇ Semestre de 2000/2ㅇ Semestre de 2000.

FRIEDMAN, M. The social responsability of business is to increase its profits. New York Times Magazine, v. 17, n. 6, p. 595-612, 1970.

. Capitalismo e liberdade. São Paulo: Artenova, 1977.

HANNIGAN, J. Sociologia ambiental. A formação de uma perspectiva social. Lisboa: Instituto Piaget, 2000.

HOMMEL, Thierry; GODARD, Olivier. Contestation sociale et stratégies de développement industriel. Application du modèle de la Gestion Contestable à la production industrielle d'OGM. Ecole Polytechnique Centre National de la Recherche Scientifique, n. 2001/015, p. 2-26, nov. 2001.

KIRSCHNER, Ana Maria. Sociologia da empresa e responsabilidade social das empresas. In: KIRSCHNER, Ana Maria; GOMES, Eduardo R.; CAPPELLIN, Paola (orgs.). Empresa, empresários e globalização. Rio de Janeiro: Relume Dumará/FAPERJ, 2002.

LAYRARGUES, Philippe P. Sistemas de gerenciamento ambiental, tecnologia limpa e consumidor verde: adelicada relação empresa-meioambiente no ecocapitalismo. Revista de Administração de Empresas, São Paulo, v. 40, n. 2, p. 88-80, abr./jun. 2000.

LEMKOV, Louis. Sociología ambiental: pensamiento socioambiental y ecología social del riesgo. Barcelona: Icária, 2002.

LIMA, J. V. R. B. C., Sociedade de risco, meio ambiente e governança empresarial. Anais IV Encontro da ANPPAS, Brasília, 2008.

As possibilidades de uma socioecologia em Amartya Sen. In: Pensamento Plural, Ano 2 - N. 3, julho/ dezembro 2008.

LEFF, Enrique. Economia, capital e cultura. Rio de Janeiro: Vozes, 2006.

LUHMANN, Niklas. Confiança. Barcelona: Anthropos; México: Universidad Iberoamericana; Santiago do Chile: Instituto de Sociologia, 2005.

Organización y decisión - Autopoiesis, acción y entendimento comunicativo. Barcelona: Anthropos; México: Universidad Iberoamericana; Santiago do Chile: Instituto de Sociologia, 2005.

MOL, Arthur, P. J. Modernizacion ecológica: transformaciones industriales y reforma ambiental. In: REDCLIFT, Michael; WOODGATE. Sociologia del medio ambiente: una perspectiva internacional. Madrid: Mcgraw-Hill/ Interamericana de Espana, 2002.

NOBRE, Marcos. Desenvolvimanto sustentável: origens e significado atual. In: ; AMAZONAS, Maurício de C. (orgs.). Desenvolvimento sustentável: a institucionalização de um conceito. Brasília: IBAMA, 2002.

SACHS, Ignacy. Rumo à ecossocioeconomia. São Paulo: Cortez, 2007.

. Desenvolvimento includente, sustentável e sustentado. Rio de Janeiro: Garamond, 2008.

SACHS, Wolfgang. Desenvolvimento sustentável. In: REDCLIFT, Michael; WOODGATE, Grahan. Sociologia del medio ambiernte: una perspectiva internacional. Madrid: Mcgraw-Hill/Interamericana de Espana, 2002.

SEN, Amartya. Desenvolvimento como liberdade. São Paulo: Companhia das Letras, 2000. 
Esfera pública ambiental - das novas relações empresa (mercado), estado e sociedade

Desigualdade reexaminada. Rio de Janeiro: Record, 2001.

Sobre ética e economia. São Paulo: Companhia das Letras, 1999.

THÉVENOT, Laurent. Équilibre et rationalité dans un univers complexe. Revue économique, n. 2, p. 147-197, março 1989.

UNGER, Roberto Mangabeira. Política: os textos centrais. São Paulo: Boitempo; Santa Catarina: Argos, 2001.

VIOLA, Eduardo. Ambiente \& Sociedade - Ano II - N. 3 - 2. Semestre de 1998.

VERDUN, R.; MEDEIROS, Rosa M. V. Relatório de Impacto Ambiental. Porto Alegre: UFRGS, 2006.

Recebido em 12/07/2011

Aprovado em 18/08/2011

Século XXI, UFSM, Santa Maria, v. 1, n. 2, p. 115-130, jul./dez. 2011 